\title{
A study of maternal risk factors and the perinatal outcome in meconium stained amniotic fluid in central referral hospital
}

\author{
Kapil Singh Niranjan*, Pesona Grace Lucksom
}

Department of Obstetrics and Gynecology, Sikkim Manipal Institute of Medical Sciences (SMU), Gangtok, Sikkim, India

Received: 11 August 2019

Accepted: 09 September 2019

*Correspondence:

Dr. Kapil Singh Niranjan,

E-mail: dr.kapilniranjan@gmail.com

Copyright: (c) the author(s), publisher and licensee Medip Academy. This is an open-access article distributed under the terms of the Creative Commons Attribution Non-Commercial License, which permits unrestricted non-commercial use, distribution, and reproduction in any medium, provided the original work is properly cited.

\section{ABSTRACT}

Background: Meconium staining of amniotic fluid (MSAF) is a significant risk factor for the subsequent development of meconium aspiration syndrome (MAS), respiratory distress and eventual respiratory failure in neonates. To learn more about the risk factors and outcomes associated with MSAF, a prospective case control study was conducted. The objective of the study was to study various maternal risk factors associated with MSAF and to study the outcome of neonates born through MASF and to compare the perinatal outcome in patients with thick and thin meconium stained amniotic fluid.

Methods: A hospital based prospective case control study was conducted comparing pregnant women with meconium stained (cases) amniotic fluid with pregnant women having clear liquor (control), 200 in each arm. Singleton pregnancies complicated with MASF were included in the cases group on the basis of predefined inclusion criteria. Various risk factors, mode of delivery, outcome of neonates and perinatal outcome in babies born through thick and thin meconium stained amniotic fluid was studied.

Results: Out of 200 patients who had MSAF 114 patients (57\%) had thick meconium stained liquor while remaining 86 patients $(43.00 \%)$ had thin meconium stained amniotic fluid. Post-maturity, pregnancy induced hypertension; oligohydramnios and prolonged labor were found to be statistically significant risk factors for MSAF. Nonreactive non-stress test and Need for cesarean section was more common in women with MSAF as compared to women with clear liquor $(\mathrm{p}<0.05)$. Common morbidities in neonates were Birth asphyxia $(15 \%)$ followed by meconium aspiration syndrome (10\%) and hypoxic ischemic encephalopathy $(15 \%)$.

Conclusions: Meconium stained amniotic fluid is more commonly associated with post-maturity, pregnancy induced hypertension, oligohydramnios and prolonged labor low APGAR score and higher incidence of birth asphyxia and NICU admissions. Appropriate management of neonates with meconium aspiration syndrome is crucial to prevent neonatal mortality.

Keywords: Maternal and neonatal outcome, Meconium stained amniotic fluid, Mode of delivery, Prolonged labour, Respiratory distress, Risk factors

\section{INTRODUCTION}

Meconium is the first substance secreted from fetal intestines and consist of intestinal epithelial cells, lanugo, mucus, amniotic fluid, bile and water. ${ }^{1,2}$ Its formation begins around 10-12 weeks of gestation and the quantity goes on increasing as the gestational age advances and it is the post-mature baby who is at a greater risk of passage of meconium in utero and its consequences like meconium aspiration syndrome (MAS). ${ }^{3}$ Meconium aspiration syndrome is one of the dreadful complications of prolonged labor, fetal hypoxia due to any cause and 
prematurity. Once the meconium is aspirated by fetus it may cause severe meconium pneumonitis, respiratory distress, acidosis and ultimately respiratory failure. ${ }^{4}$ Extensive neonatal care, surfactant therapy and ventilatory management is required for babies developing respiratory distress secondary to meconium aspiration and despite extensive medical care MAS may prove fatal in many cases. ${ }^{5}$ The various hypothesis put forward as the triggering event for in-utero passage of meconium include fetal hypoxia, vagal stimulation causing increased peristalsis and relaxation of anal sphincter and passage of meconium as a consequence of normal gastrointestinal tract maturation as the gestational age advances. ${ }^{6}$ Fetal hypoxia causing increased peristalsis and passage of meconium appears to be plausible as there is increased incidence of passage of meconium in many cases where fetal distress is diagnosed on the basis of fetal bradycardia or abnormal doppler parameters. ${ }^{7}$ On the contrary no definite cause is found in many cases where there is meconium staining of amniotic fluid first noted during rupture of membranes. It is possible that different mechanisms may be at play in different patients. Like in post mature babies increased incidence of meconium stained amniotic fluid may represent maturation of gut while in cases with fetal distress, hypoxia causing increased peristalsis and consequently passage of meconium may be the cause. ${ }^{8}$

Irrespective of the cause of passage of meconium in utero it is important to prevent its aspiration as it will invariably cause pneumonitis, emphysema due to ball valve mechanism, acidosis and in severe cases respiratory failure and neonatal death. ${ }^{9}$ For this pregnancy with post maturity, fetal compromise or fetal distress should be identified in time. ${ }^{10}$ Umbilical artery doppler showing absence or reversal of diastolic flow, decrease or loss of fetal movements, fetal bradycardia and fetal scalp blood $\mathrm{pH}$ indicative of acidosis are some of the important features which may suggest fetal hypoxia. In all such cases appropriate measures must be taken to prevent fetal morbidity and mortality. ${ }^{11}$

Meconium stained amniotic fluid may be a normal phenomenon in post-maturity and has little significance unless it is associated with variations in fetal heart rate and other signs of fetal hypoxia. Nonetheless there are always chances that the fetus may make gasping in-utero more hazardous in presence of meconium stained amniotic fluid. ${ }^{12}$ Unless proper resuscitative measures are taken immediately after the delivery aspiration of meconium may take place which is usually followed by major pathological consequences that include airway obstruction, surfactant dysfunction, chemical pneumonitis and pulmonary hypertension. The consequences of pathological processes may cause secondary complications such as persistent pulmonary hypertension in newborn (PPHN), right to left shunts due to pulmonary hypertension, diffuse pneumonitis due to enzymes, bile salts and free fatty acids present in meconium. Surfactant dysfunction may result in diffuse atelectasis and airway obstruction may result in hyperinflation, pneumothorax and pneumomediastinum. ${ }^{13}$

Maternal risk factors associated with meconium stained amniotic fluid and consequently meconium aspiration syndrome include maternal pathologies such as preeclampsia and eclampsia, anemia, oligohydramnios, prolonged labor, maternal infections such as chorioamnionitis, maternal substance abuse such as tobacco or cocaine and placental insufficiency of any cause. ${ }^{14}$ Though meconium aspiration can occur in any gestation complicated or uncomplicated, treating obstetrician must be aware of presence of maternal risk factors so that appropriate preventive and therapeutic measures can be taken in time. ${ }^{15}$ We conducted this study to find out the maternal risk factors and their association with the incidence of meconium aspiration in newborn. Moreover, outcome in children born with meconium stained amniotic fluid was also studied with the help of data found during this study.

\section{METHODS}

This was a hospital based prospective case control study conducted at a tertiary care medical college in the department of obstetrics and gynaecology study was conducted over a period of one and half year from Jan2017 to June 2018. Women with term pregnancy ( $\geq 37$ weeks) who were diagnosed to have meconium stained liquor during labour were taken as cases and women at ( $\geq 37$ weeks) who had clear liquor during labour were taken as controls.

Study was conducted after approval from the institutional ethical committee. Women were included in the study after obtaining consent for the same. Women who had meconium stained liquor during labour or when clear amniotic fluid became meconium stained during course of labour were included as cases while women who had clear liquor throughout labour were included as controls. The study was conducted on pregnant women with gestational age from $\geq 37$ weeks of pregnancy in labor after taking informed consent.

Data was collected from antenatal history and clinical examination. Following selection of cases, a detailed history regarding age, gravida and parity, past obstetrical history, menstrual history, socioeconomic status and history of present pregnancy, history of medical and surgical disorders were noted from the pregnant women under study.

A detailed history was taken with a special emphasis on associated maternal risk factors like pre-eclampsia, gestational diabetes, history of fever and substance abuse. Ultrasound reports were studied and any abnormality like oligohydramnios or polyhydramnios was noted down. Method of delivery like vaginally, forceps delivery or LSCS was noted. General and systemic examination was done. Obstetrical examination was done noting the 
presentation, position, height of fundus, amount of amniotic fluid, fetal heart rate, uterine contraction, pelvic status. When MSAF appeared along with rupture of membrane it was collected and clinically graded thorough and quick vaginal examination was done to assess the state of cervix, station of fetal head, and exclusion of cord prolapse and to note the colour and consistency of AF. MSAF was collected by introducing Sim's speculum under aseptic precaution and material taken into a clear test tube for clinical gradation according to the colour and consistency. When AF was thinly stained with greenish yellow in colour, it was graded as thin meconium stained. When AF was dark green or tarry black or muddy in colour and of thick consistency it was considered as thick meconium stained. Study cases were grouped into thin and thick meconium stained amniotic fluid group on the basis of consistency of meconium.

Intrapartum cardiotocographic (CTG), APGAR scores at 1 and 5 minutes, Weight and gender of the newborns was noted. All the babies delivered were kept under observation for 24hours. Babies who were normal and did not develop any complications within 24hours after birth were placed mother-side. Babies who developed any sign of respiratory distress within 24hours were shifted to NICU. Babies who initially were shifted to mother and developed signs of respiratory distress were also transferred to NICU. Babies were followed-up up to 7 day and their clinical condition was assessed and any abnormalities were recorded. Death and its cause during hospital stay within first week of neonatal life were also recorded.

\section{Inclusion criteria}

- Term pregnancy ( $\geq 37$ weeks) in labour

- Cephalic presentation

- Live singleton pregnancy.

\section{Exclusion criteria}

- Antepartum hemorrhage

- Malpresentations, multiple pregnancy

- Foetus with congenital malformations

- Intrauterine foetal death

- Patient who refused to give consent

- Severe Intrapartum foetal asphyxia.

\section{Statistical analysis}

Data was entered in Microsoft excel 2013 and then transferred to SPSS version 16 for analysis. Data were described using descriptive data like mean and percentages. $\mathrm{P}$ value less than 0.05 was taken as statistically significant.

\section{RESULTS}

This was a hospital based prospective case control study conducted at Central referral hospital (CRH) in the department of Obstetrics and Gynaecology for a period of one and half year. Two hundred women with meconium stained liquor were taken as cases and two hundred women with clear liquor during delivery were taken as controls for the study. Out of 200 patients who had meconium stained amniotic fluid 114 patients (57\%) had thick meconium stained liquor while remaining 86 patients $(43.00 \%)$ had thin meconium stained amniotic fluid (Figure 1).

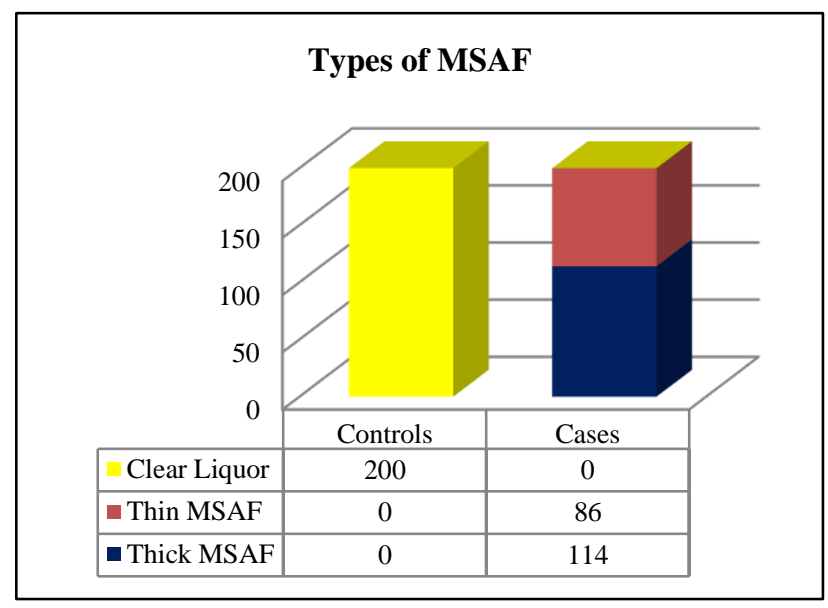

Figure 1: Types of meconium stained amniotic fluid in studied cases.

The analysis of the age groups of the patients having meconium stained amniotic fluid showed that the most commonly affected age group was between 21-25 years (36.50\%) followed by $26-30$ years $(29.50 \%)$ and 20 years or below $(19.00 \%)$. There was no statistically significant difference in age groups of cases and control $(\mathrm{p}=0.54)$ (Figure 2).

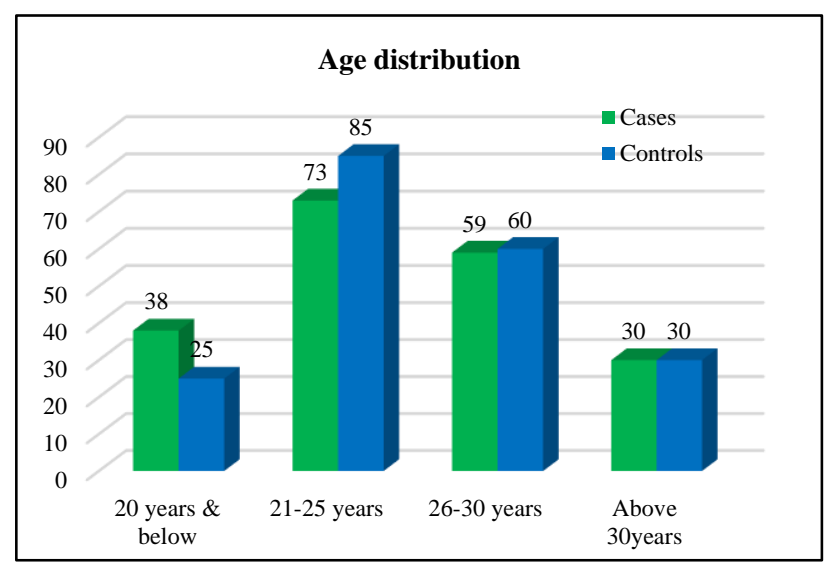

Figure 2: Age distribution of the studied cases.

Incidence of meconium stained amniotic fluid was more common in Primigravida $(55.00 \%)$ compared to Multigravida $(45.00 \%)$. Though this difference was not found to be statistically significant $(\mathrm{P}>0.05)$ (Figure 3 ). 


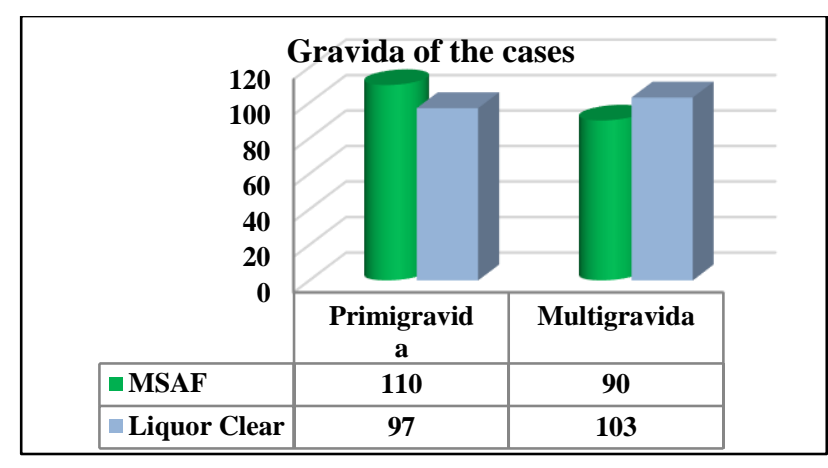

Figure 3: Gravida of the studied cases.

Majority of the women in the case and control groups were in the 37-40 weeks of gestation.
Table 1: Distribution of cases and controls on the basis of gestational age.

\begin{tabular}{|lll|}
\hline Gestational age & Cases no. $(\%)$ & Controls no. $(\%)$ \\
\hline $37-40$ weeks & $140(70)$ & $160(80)$ \\
\hline $40-42$ weeks & $35(17.5)$ & $35(17.5)$ \\
\hline$>42($ post term) & $25(12.5)$ & $5(2.5)$ \\
\hline Mean age & $39.42 \pm 2.05$ & $39.22 \pm 2.01$ \\
\hline Total & $\mathbf{2 0 0 ( 1 0 0 )}$ & $\mathbf{2 0 0}(\mathbf{1 0 0})$ \\
\hline
\end{tabular}

$P$ value $>0.05$ (Not significant)

There was no statistically significant difference in mean gestational age of control and cases. In patients with meconium stained amniotic fluid post maturity was seen in $25(12.50 \%)$ patients while only $5(2.50 \%)$ patients had post maturity in control group (Table 1).

Table 2: Maternal risk factors associated with meconium stained amniotic fluid.

\begin{tabular}{|llll|}
\hline Risk factors & MSAF no. $(\%)$ & Clear liquor no. $(\%)$ & P-value \\
\hline Post maturity & $25(12.5)$ & $5(2.5)$ & $<0.05$ (Significant) \\
\hline Pregnancy induced hypertension (PIH) & $22(11)$ & $3(1.5)$ & $<0.05$ (Significant) \\
\hline Anemia & $12(6)$ & $10(5)$ & $>0.05$ (Not significant) \\
\hline IUGR & $2(1)$ & $7(3.5)$ & $>0.05$ (Not significant) \\
\hline Oligohydramnios & $32(16)$ & $5(2.5)$ & $<0.05$ (Significant) \\
\hline Prolonged labour & $33(16.5)$ & $8(4)$ & $<0.05$ (Significant) \\
\hline Multiple risk factor & $29(14.5)$ & $5(2.5)$ & $<0.05$ (Significant) \\
\hline No risk factors & $45(22.5)$ & $157(78.5)$ & \\
\hline Total & $\mathbf{2 0 0}(\mathbf{1 0 0})$ & $\mathbf{2 0 0}(\mathbf{1 0 0})$ & \\
\hline
\end{tabular}

Table 3: Stage of labour when meconium was detected and mode of delivery.

\begin{tabular}{|c|c|c|c|c|c|}
\hline \multirow{2}{*}{$\begin{array}{l}\text { Stage of labour when meconium } \\
\text { was detected }\end{array}$} & \multirow{2}{*}{ Grade of meconium } & \multirow{2}{*}{ No. of cases } & \multicolumn{3}{|c|}{ Mode of delivery } \\
\hline & & & NVD & Vacuum/forceps & LSCS \\
\hline \multirow{2}{*}{ Latent phase } & Thin & 25 & 8 & 7 & 10 \\
\hline & Thick & 47 & 7 & 0 & 40 \\
\hline \multirow{2}{*}{ Active phase } & Thin & 45 & 16 & 13 & 16 \\
\hline & Thick & 53 & 5 & 3 & 45 \\
\hline \multirow{2}{*}{$2^{\text {nd }}$ Stage } & Thin & 16 & 4 & 5 & 7 \\
\hline & Thick & 14 & 4 & 3 & 7 \\
\hline Total & & 200 & 44 & 31 & 125 \\
\hline
\end{tabular}

The analysis of risk factors showed that $45(22.5 \%)$ women had no risk factors. Most common single risk factor associated with MSAF was found to be prolonged labour $(16.5 \%)$ followed by Oligohydramnios $(16 \%)$ post maturity $(12.50 \%)$ and PIH (11\%). In $14.50 \%$ of women with MSAF multiple risk factors were present compared to $2.5 \%$ of women who had clear liquor which showed statistical significance. There were also statistical significance among women who had post maturity (21.5\% in case versus $2.5 \%$ in control group) $\mathrm{PIH}(11 \%$ in case versus $1.5 \%$ in control group), oligohydramnios (16.0\% in case versus $2.5 \%$ in control group) and prolonged labour (16.5\% in cases versus $4 \%$ in control group) (Table 2).

The study of association of non-stress test and meconium staining of amniotic fluid showed that out of 200 patients with meconium stained amniotic fluid 135 (67.50\%) women had a non-reactive non-stress test while in control group only $15(7.50 \%)$ women had a non-reactive nonstress test. The difference was found to be statistically significant $(\mathrm{P}<0.05)$ (Figure 4$)$. 


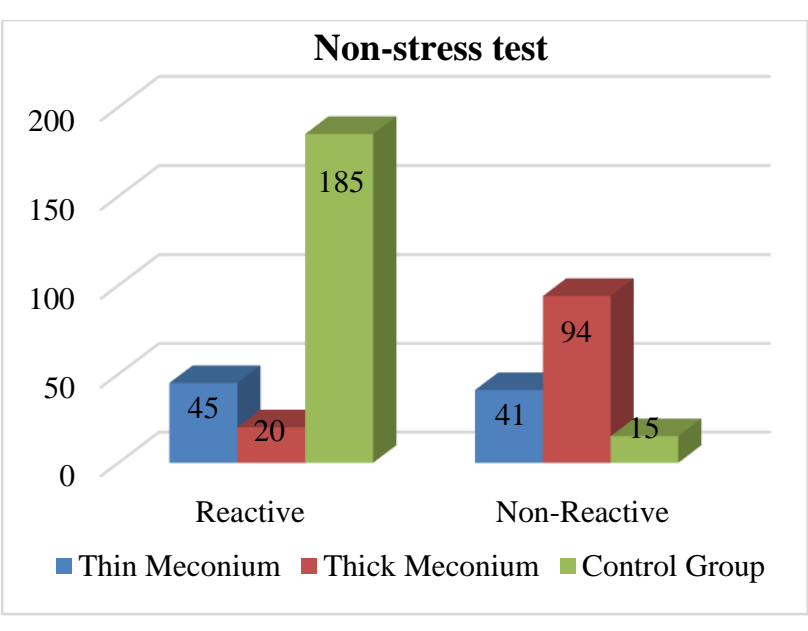

Figure 4: Evaluation of non-stress test in study population.

In this study, meconium stained amniotic fluid was detected most commonly in active phase of labour $(49.00 \%)$ followed by latent phase $(36.00 \%)$ and $2^{\text {nd }}$ stage of labour $(15.00 \%)$. The most common mode of delivery in meconium stained amniotic fluid was by LSCS $(62.50 \%)$ followed by normal vaginal delivery $(22.00 \%)$ and vacuum/forceps assisted delivery $(15.50 \%)$ (Table 3 ).

The analysis of mode of delivery in the sub group of cases (thin and thick meconium stained liquor) was done and it was found that out of 114 cases with thick meconium stained amniotic fluid 92 delivered by LSCS while out of 86 patients with thin meconium stained amniotic fluid 33 patients had to be delivered by LSCS. In control group out of 200 pregnant women 40 patients delivered by LSCS. After meconium stained amniotic fluid was detected majority of the babies were delivered by LSCS $(62.50 \%)$ while in control group LSCS was done in 40 patients $(20 \%)$. The most common indication for LSCS in control group was found to be previous LSCS $(8 \%)$ followed by cephalopelvic disproportion (4\%), fetal distress (2\%) and non-progression of labor (2\%). In remaining $4 \%$ LSCS was done for conditions such as IUGR, patient request, and non-reassuring NST. The difference in LSCS rates in control and cases groups was found to be statistically significant $(\mathrm{P}<0.05)$ (Table 4).

Table 4: Need for LSCS in studied cases.

\begin{tabular}{|c|c|c|c|}
\hline \multirow[b]{2}{*}{ Mode of delivery } & \multicolumn{2}{|c|}{ Meconium stained amniotic fluid } & \multirow[b]{2}{*}{ Control group cases $(\%$} \\
\hline & $\begin{array}{l}\text { Thick meconium } \\
\text { no. of cases }(\%)\end{array}$ & $\begin{array}{l}\text { Thin meconium } \\
\text { no. of cases }(\%)\end{array}$ & \\
\hline Normal delivery & $16(8)$ & $28(14)$ & $140(70)$ \\
\hline Vaccum/forceps extraction & $6(3)$ & $25(12.5)$ & $20(10)$ \\
\hline LSCS & $92(46)$ & $33(16.5)$ & $40(20)$ \\
\hline Total & $114(57)$ & $86(43)$ & $200(100)$ \\
\hline
\end{tabular}

Meconium stained amniotic fluid and need for LSCS - P value $<0.05$ (Significant)

Table 5: Distribution of birth weights in neonates.

\begin{tabular}{|lll|}
\hline Birth weight $(\mathrm{kg})$ & Cases group $(\%)$ & Control group (\%) \\
\hline Low Birth Weight $(<2.5)$ & $42(21)$ & $46(23)$ \\
\hline Normal Birth weight $(\geq 2.5-3.9)$ & $158(79)$ & $152(76)$ \\
\hline Macrosomia $(\geq 4)$ & $0(0)$ & $2(1)$ \\
\hline Mean (std. deviation) & $2.56 \pm 1.12$ & $2.72 \pm 1.42$ \\
\hline Total & $\mathbf{2 0 0}(\mathbf{1 0 0})$ & $\mathbf{2 0 0}(\mathbf{1 0 0})$ \\
\hline
\end{tabular}

Difference in distribution of birth weight $\mathrm{P}>0.05$ (Not significant)

Table 6: APGAR score at 1 and 5 minute in the neonates.

\begin{tabular}{|c|c|c|c|c|}
\hline \multirow{2}{*}{ Amniotic fluid } & \multicolumn{2}{|c|}{ APGAR score at 1 minute } & \multicolumn{2}{|c|}{ APGAR score at 5 minute } \\
\hline & $<6$ & $\geq 6$ & $<6$ & $\geq 6$ \\
\hline Thin & 61 & 53 & 5 & 81 \\
\hline Thick & 9 & 77 & 39 & 75 \\
\hline Total MSAF & $70(35 \%)$ & $130(65 \%)$ & $44(22 \%)$ & $156(78 \%)$ \\
\hline Clear & $20(10 \%)$ & $180(90 \%)$ & $18(9 \%)$ & $182(91 \%)$ \\
\hline
\end{tabular}

Statically significant difference in APGAR Scores at 1 and 5 minute $(\mathrm{P}<0.05)$ 
The analysis of the birth weights in the study showed that in case group $158(79.00 \%)$ neonates had normal birth weight while $42(21.00 \%)$ babies were low birth weight. While in control group normal birth weight was seen in $152(76.00 \%)$ neonates and $46(23.00 \%)$ babies were low birth weight. In control group 2 babies were found to have weight more than $4 \mathrm{~kg}$ (macrosomia) while there were no babies weighing $>4 \mathrm{~kg}$ in the case group. There was no statistical association between MSAF and birth weight (Table 5).
The present study shows that meconium staining was significantly associated with low APGAR score at one minute. $70(35 \%)$ neonates in meconium group had APGAR score less than 6 while only $20(10 \%)$ in control group had APGAR score less than 6. Thick meconium stained liquor was more commonly associated with lower APGAR scores at 1 as well as 5 minutes than thin meconium stained liquor. The difference was found to be statistically significant $(\mathrm{P}<0.05)$ (Table 6).

Table 7: Need for resuscitation in thick and thin meconium stained amniotic fluid.

\begin{tabular}{|llll|}
\hline Ammiotic fluid & Oxygen/resuscitation required & No resuscitation/oxygen required \\
\hline \multirow{3}{*}{ MSAF } & Thick meconium & 40 & 74 \\
\cline { 2 - 4 } & Thin meconium & 30 & 56 \\
\cline { 2 - 4 } & Total & $\mathbf{7 0}$ & $\mathbf{1 3 0}$ \\
\hline Liquor clear & 30 & 170 \\
\hline
\end{tabular}

Statically significant difference in need for resuscitation $(\mathrm{P}<0.05)$

Table 8: Morbidity in neonates born with meconium stained amniotic fluid.

\begin{tabular}{|llll|}
\hline Morbidity & $\begin{array}{l}\text { Meconium stained amniotic fluid } \\
\text { Thick meconium } \\
\text { stained }(\mathbf{\%})\end{array}$ & $\begin{array}{l}\text { Thin meconium } \\
\text { stained }(\%)\end{array}$ & $\begin{array}{l}\text { Liquor clear } \\
(\%)\end{array}$ \\
\hline Asphyxia & $30(15)$ & $9(4.5)$ & $20(10)$ \\
\hline Meconium aspiration syndrome & $20(10)$ & $8(4)$ & $0(0)$ \\
\hline Neonatal pneumonia & $10(5)$ & $3(1.5)$ & $7(3.5)$ \\
\hline Hypoxic ischemic encephalopathy & $15(7.5)$ & $9(4.5)$ & $1(0.5)$ \\
\hline Persistent pulmonary hypertension & $9(4.5)$ & $5(2.5)$ & $0(0)$ \\
\hline Early/ late onset sepsis & $11(5.5)$ & $4(2)$ & $17(8.5)$ \\
\hline Total & $\mathbf{9 0}(\mathbf{4 5})$ & $\mathbf{3 8}(\mathbf{1 9})$ & $\mathbf{4 4}(\mathbf{2 2})$ \\
\hline
\end{tabular}

Statically significant difference in morbidity $(\mathrm{P}<0.05)$.

40 Neonates born through thick meconium stained amniotic fluid needed some form of resuscitative measures including endotracheal intubation and IPPV $(10 \%)$, intubation and suctioning $(5.00 \%)$, bag and mask ventilation (3\%). Only Oxygen inhalation was needed in $4(2 \%)$ neonates. In babies born through thin meconium stained amniotic fluid 30 neonates required either oxygen inhalation or some form of resuscitation. When comparative study was done among the meconium stained amniotic fluid and clear liquor, 30 (15\%) neonate in the clear liquor group required some form of resuscitation while $70(35 \%)$ in the MSAF needed resuscitation which was statistically significant $(\mathrm{P}<0.05)$. In control group only $30(15 \%)$ patients required some or the other form of resuscitation. The difference was found to be statistically significant $(\mathrm{P}<0.05)$ (Table 7).

Morbidities in child both with and without MSAF were studied. Morbidities associated with meconium stained amniotic fluid included birth asphyxia (19.50\%) followed by meconium aspiration syndrome (14\%), Hypoxic ischemic encephalopathy (12.00\%) and sepsis (07.50\%). In control group Asphyxia (10\%), sepsis (8.50\%) and neonatal pneumonia $(3.50 \%)$ were commonly seen morbidities (Table 8).

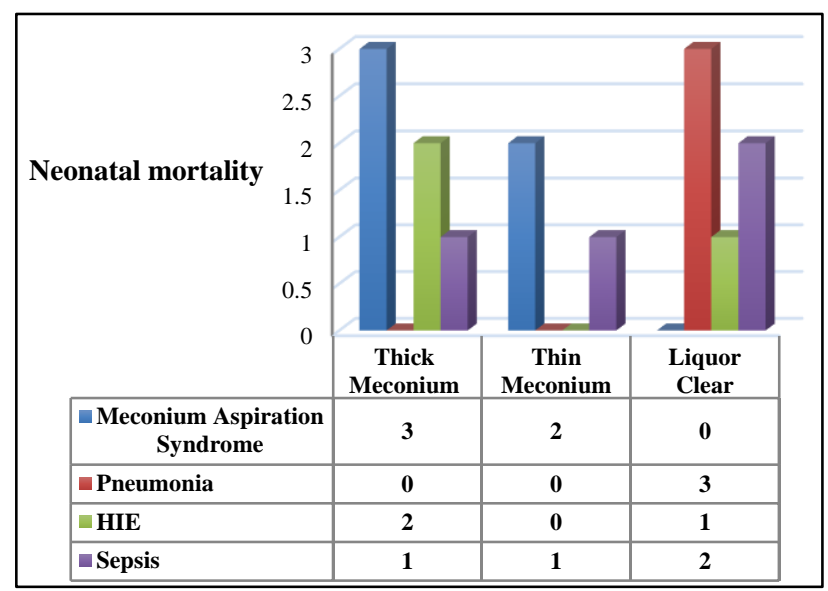

Figure 5: Neonatal mortality in studied cases. 
Finally, the analysis of neonatal mortality patterns of the studied cases showed that the $6(3.00 \%)$ neonates in thick meconium stained group died during neonatal period while $3(1.50 \%)$ neonates in thin meconium stained group died. The overall neonatal mortality in meconium stained group and control group was found to be $4.50 \%$ and $3.00 \%$ respectively (Figure 5).

\section{DISCUSSION}

Meconium stained amniotic fluid (MSAF) is a commonly encountered problem during obstetric practice. Proper management of patients with MSAF is crucial for fetal wellbeing during intrapartum period. Not all the babies born through meconium stained amniotic fluid develop meconium aspiration syndrome but those who develop meconium aspiration syndrome usually develop respiratory distress and complications such as pneumonia, atelectasis and eventual respiratory failure. When authors compared the incidence of thin and thick meconium stained amniotic fluid with other studies it was found that the authors like Raman et al, and Fischer et al, reported a higher rate of thick meconium stained amniotic fluid while others such as Sedaghatian et al, reported a higher rate of thin meconium stained amniotic fluid. ${ }^{16-18}$

The analysis of the age groups of the patients showed that in our study the most common age group in cases was more than 21-25 years $(36.5 \%)$ followed by $26-30$ years (29.5\%). Similar age distribution was reported by the authors like Mundhara R, while a higher percentage of women was found in the age group of 20-30 years in the study conducted by the authors such as sandu et al. ${ }^{19,20}$

In our study majority of the women with meconium stained amniotic fluid were primigravida (55\%). Similar results were reported by the authors such as Harikumar et al, who reported that $69 \%$ of the women found to have meconium stained amniotic fluid were primigravida. ${ }^{21}$ Other authors such as Gokhru K et al, and Kavyashree et al, found that MSAF was more common in primigravida and multigravida respectively. ${ }^{22,23}$

In our study it was found that majority of the pregnant women found to have meconium stained amniotic fluid were having the gestational age of $37-40$ weeks (70\%). Other studies such as those conducted by Sori DA et al found that the meconium stained amniotic fluid was more common in between the age group of 40-42 years while the authors such as Desai et al reported that that meconium aspiration syndrome may be equally distributed among different gestational ages beyond 37 weeks of gestation. ${ }^{24,25}$

In our study most common risk factors found to be associated with meconium stained amniotic fluid were found to be prolonged labor (16.5\%) followed by post maturity (12.5\%) and oligohydramnios (10\%). The authors like Sundaram et al, could that $90 \%$ of the patients with MSAF were also having oligohydramnios as seen on ultrasound. ${ }^{26}$ Similarly Vinaya et al, found that the most common risk factors associated with MSAF were oligohydramnios $(68.12 \%)$ followed by prolonged labour $(22 \%)$ and hypertension $(26.5 \%) .^{27}$

In this study amongst the patients with thick meconium stained liquor $80.70 \%$ patients were delivered by lower segment cesarean section while $38.37 \%$ patients with thin meconium stained liquor were delivered by LSCS. Similar high LSCS rates in patients with thick MSAF have been reported by authors such as Singh $\mathrm{P}$ et al, and Qadir et al, who reported that $60 \%$ and $56.2 \%$ patients were delivered by LSCS after having found to have thick MSAF. ${ }^{28,29}$

APGAR score at 1 minute was analyzed in all the neonates. Since APGAR score of less than 6 is suggestive of birth asphyxia, neonates were divided on the basis of whether they had more or less than 6 APGAR score at 1 minute. In our study 61 out of 114 neonates with thick meconium stained amniotic fluid had APGAR score less than 6 whereas only 9 patients out of 86 patients with thin meconium stained amniotic fluid had APGAR score less than 6 at 1 minute indicating that birth asphyxia is more likely to occur in neonates born through thick meconium stained amniotic fluid. This is in contrast to the study conducted by Vaghela et al, who reported that APGAR less than 6 suggestive of birth asphyxia was more common in thin meconium stained amniotic fluid. ${ }^{30}$

In this study a very high percentage of neonates $(64 \%)$ have some or the other form of morbidity in cases (MSAF) group. As compared to cases control group had lower morbidity and only $22 \%$ neonates were found to have some or the other form of morbidity. Our results were similar to the results reported by Erum $\mathrm{S}$ et al, who reported morbidity in $46 \%$ of the neonates born through meconium stained amniotic fluid. ${ }^{31}$ A lower morbidity rates were reported by Arun et al, who reported morbidity in only $13.76 \%$ of the neonates born through meconium stained amniotic fluid. ${ }^{32}$

Finally the analysis of mortality showed that out of 200 babies born through meconium stained amniotic fluid 9 $(4.5 \%)$ babies died during perinatal period. Out of these 9 neonates $6(3 \%)$ belonged to thick meconium stained group and $3(1.5 \%)$ belonged to thin meconium stained group. Debdas et al, have reported similar perinatal mortality figures $(3 \%)$ while Narang et al, have found a slightly higher perinatal mortality in neonates born through meconium stained amniotic fluid $(7.7 \%) .{ }^{33,34}$ Ziadehet al, have reported very minimal perinatal mortality $(1 \%)$ as compared to other studies. ${ }^{35}$

\section{CONCLUSION}

Post-maturity, pregnancy induced hypertension; oligohydramnios and prolonged labor were found to be significant risk factors for MSAF. Birth asphyxia, need for resuscitation and hypoxic ischemic encephalopathy 
were significant consequences in babies born through MSAF. There was no statistically significant differences in the neonatal mortality in babies born to women with meconium stained and clear liquor (control group). Appropriate management of MAS may be one of the key factors responsible for decreased neonatal mortality.

Funding: No funding sources

Conflict of interest: None declared

Ethical approval: The study was approved by the Institutional Ethics Committee

\section{REFERENCES}

1. Holtzman BR, Banzhaf WC, Silver RK, Hageman RJ. Perinatal management of meconium stained amniotic fluid. Clin Perinatol. 1989;16:825-38.

2. Lopez-Rodriguez E, Echaide M, Cruz A, Taeusch HW, Perez-Gil J. Meconium impairs pulmonary surfactant by a combined action of cholesterol and bile acids. Biophys J. 2011;100(3):646-55.

3. Wiedemann JR, Saugstad AM, Barnes-Powell L, Duran K. Meconium aspiration syndrome. Neonatal Netw. 2008;27(2):81-7.

4. Singh SN, Srivastava R, Singh A, Tahazzul M, Kumar M, Kanta C, Chandra S. Respiratory distress including meconium aspiration syndrome in vigorous neonates born through meconium stained amniotic fluid: incidence, onset, severity and predictors at birth. Indian J Pediatr. 2013;80(7):538-43.

5. Davis RO, Philips JB, Harris BA, Wilson ER, Huddleston JF. Fatalmeconium aspiration syndrome occurring despite airway management considered appropriate. Am J Obstet Gynecol. 1985;151(6):7316.

6. Galal M, Symonds I, Murray H, Petraglia F, Smith R. Postterm pregnancy. Facts, Views and Vision ObGyn. 2012;4(3):175.

7. Gudmundsson S, Dubiel M. Doppler velocimetry in the evaluation of fetal hypoxia. J Perinat Med. 2001;29(5):399-407.

8. Anderson GG. Post-maturity: a review. Obstet Gynecol Surv. 1972;27(2):65-73.

9. Lin HC, Su BH, Lin TW, Peng CT, Tsai CH. Risk factors of mortality in meconium aspiration syndrome: review of 314 cases. Acta paediatrica Taiwanica Taiwan er ke yi xue hui za zhi. 2004;45(1):30-4.

10. Whitfield JM, Charsha DS, Chiruvolu A. Prevention of meconium aspiration syndrome: an update and the Baylor experience. Proceedings (Baylor University Medical Center). 2009;22(2):128-31.

11. Mundhra R, Agarwal M. Fetal Outcome in Meconium Stained deliveries. J Clin Diagn Res. 2013;7(12):2874-6.

12. Ahanya SN, Lakshmanan J, Morgan BL, Ross MG. Meconium passage in utero: mechanisms, consequences, and management. Obstet Gynecol Surv. 2005;60(1):45-56.
13. Kopincova J, Calkovska A. Meconium-induced inflammation and surfactant inactivation: specifics of molecular mechanisms. Pediatr Res. 2016;79(4):51421.

14. Usta IM, Mercer BM, Sibai BM. Risk factors for meconium aspiration syndrome. Obstet Gynecol. 1995;86(2):230-4.

15. Liu WF, Harrington T. Delivery room risk factors for meconium aspiration syndrome. Am J Perinatol. 2002;19(7):367-78.

16. Raman TR, Jayaprakash D. Neonatal outcome in meconium stained deliveries: a prospective study. Med J Arm Forces India. 1997;53(1):15-8.

17. Fischer C, Rybakowski C, Ferdynus C, Sagot P, Gouyon JB. A population-based study of meconium aspiration syndrome in neonates born between 37 and 43 weeks of gestation. Int $J$ Pediatr. 2012;2012:321545.

18. Sedaghatian MR, Othman L, Hossain MM, Vidyasagar D. Risk of meconiumstained amniotic fluid in different ethnic groups. J Perinatol. 2000;20(4):257-61.

19. Mundhra R, Agarwal M. Fetal outcome in meconium stained deliveries. J Clin Diagn Res. 2013;7(12):2874-6.

20. Sandhu SK, Singh J. Harpreet khora, Harleen Kaur: J Obst Gyn India. 1993;43:528.

21. Harikumar S. Study on meconium stained fluidperinatal outcome. Int $\mathbf{J}$ Reprod Contracept Obstet Gynecol. 2018;7:587-95.

22. Gokhroo K, Sharma U. Various maternal factors responsible for meconium stained amniotic fluid. $\mathbf{J}$ Obstet Gynecol India. 2001;51:6.

23. Kavyashree HS, Suma KB. Study on effect of nature of meconium stained amniotic fluid on perinatal outcome. J Med Sci Clin Res. 2015;3(6):6317-24.

24. Sori DA, Belete A, Wolde M. Meconium stained amniotic fluid: factors affecting maternal and perinatal outcomes at Jimma University specialized teaching hospital, south west Ethiopia. Gynecol Obstet (Sunnyvale). 2016;6:394.

25. Desai DS, Maitra N, Patel P. Fetal heart rate patterns in patients with thick meconium. Contracep Obstet Gynecol. 2017;6:1030-5.

26. Sundaram R, Murugesan A. Risk factors for meconium stained amniotic fluid and its implications. Int J Reprod Contracept Obstet Gynecol. 2016;5:2503-6.

27. Pendse V. Meconium stained Liquor amnii: its significance and effect on fetal outcome. J Obstet Gynecol India. 1983;33:66-9.

28. Singh P, Soren SN. A study of perinatal outcome in meconium stained amniotic fluid. MedPulse Int Med J. 2017;4(1):6-13.

29. Qadir S, Jan S, Chachoo JA, Parveen S. Perinatal and neonatal outcome in meconium stained amniotic fluid. Int $\mathrm{J}$ Reprod Contracept Obstet Gynecol. 2016;5:1400-5. 
30. Vaghela HP, Deliwala K, Shah P. Fetal outcome in deliveries with meconium stained liquor. Int $\mathbf{J}$ Reprod Contracept Obstet Gynecol. 2014;3:909-12.

31. Shaikh EM, Mehmood S, Shaikh MA. Neonatal outcome in meconium stained amniotic fluid-one year experience. J Pak Med Assoc. 2010;60(9):7114.

32. Nayek AH, Dalal AR. Meconium staining of amniotic fluid - significance and fetal outcome. J Obstet Gynaecol. 1991;41:480-3.

33. Debdas AK, Kaur T. Meconium stained liquor: reappraisal. J Obstet Gynaecol India. 1981;31:924-9.

34. Narang A, Nair PMC, Bhakoo ON, Vashisht K. Management of meconium stained amniotic fluid: a team approach. Indian Pediatr. 1993;30:9.
35. Ziadeh SM, Sunna E. Obstetrics and peninatal outcome of pregnancies with - term labour and meconium stained amniotic fluid. Arch Gynaecol Obstet. 2000;264(2):84-7.

Cite this article as: Niranjan KS, Lucksom PG. A study of maternal risk factors and the perinatal outcome in meconium stained amniotic fluid in central referral hospital. Int J Reprod Contracept Obstet Gynecol 2019;8:4146-54. 